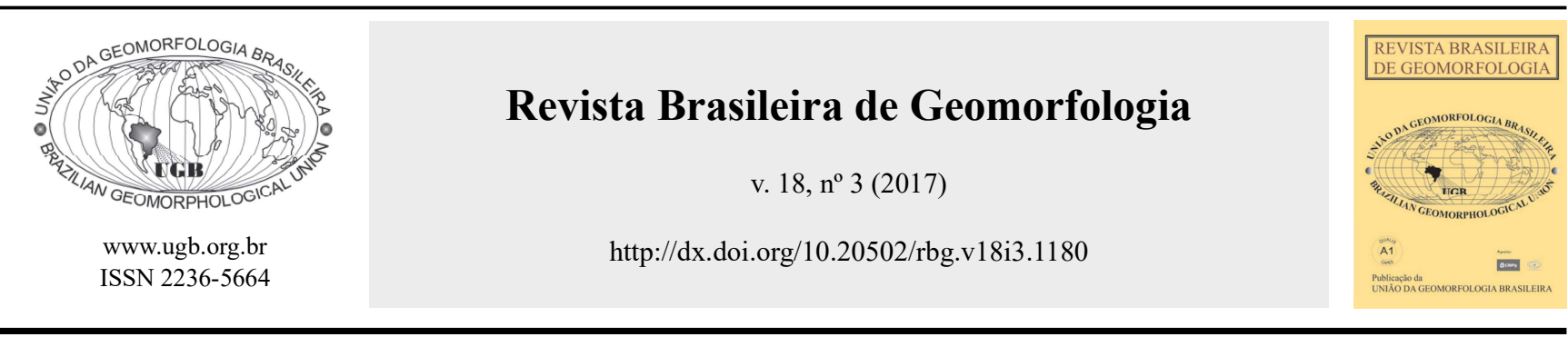

\title{
MORFOGÊNESE DA CHAPADA DAS MESAS (MARANHÃO- TOCANTINS): PAISAGEM CÁRSTICA E POLIGENÉTICA
}

\section{MORPHOGENESIS OF CHAPADA DAS MESAS (MARANHÃO- TOCANTINS): KARSTIC AND POLIGENETIC LANDSCAPE}

\author{
Fernanda Pereira Martins \\ Departamento de Geografia, Universidade Federal de Minas Gerais \\ Av. Antonio Carlos 627, Belo Horizonte, Minas Gerais. CEP: 31270-901. Brasil \\ Email: martinsgeo@hotmail.com.br \\ André Augusto Rodrigues Salgado \\ Departamento de Geografia, Universidade Federal de Minas Gerais \\ Av. Antônio Carlos 627, Belo Horizonte, Minas Gerais. CEP: 31270-901. Brasil \\ Email: aarsalgadoufmg@gmail.com
}

Helen Nébias Barreto

Departamento de Geociências, Universidade Federal do Maranhão Av. dos Portugueses 1996, São Luís, Maranhão. CEP:65080-805. Brasil

Email: helennebias@yahoo.com.br

Informações sobre o Artigo

Recebido (Received):

30/11/2016

Aceito (Accepted):

08/06/2017

\section{Palavras-chave:}

Morfogênese; Chapada das

Mesas; Arenito; Paleocarste;

Isótopo Cosmogênico ${ }^{10} \mathrm{Be}$.

\section{Keywords:}

Morphogenesis; Chapada das Mesas; Sandstone; Paleokarst;

${ }^{10} \mathrm{Be}$ Cosmogenic Nuclide.

\section{Resumo:}

A Chapada das Mesas, Maranhão/Tocantins, possui uma das paisagens mais fidedignas às unidades de chapadas no Brasil. Entretanto, esta região foi pouco estudada, principalmente em termos de gênese de sua paisagem. Neste contexto, insere-se o presente trabalho que analisou os processos que influenciaram na morfogênese da Chapada das Mesas através da correlação entre a litologia, morfoestrutura e o sistema de drenagem regional. Para tanto, os métodos de análise utilizados, foram: (a) parâmetros morfométricos, (b) mensuração de processos denudacionais de longo termo $\left({ }^{10} \mathrm{Be}\right)$ e, (c) trabalhos de campo. Com base nas análises realizadas concluiu-se que a estrutura regional influenciou diretamente a configuração da drenagem pretérita e atual, potencializando a morfogênese dessa paisagem devido a processos internos associados a um antigo sistema de drenagem subterrânea típico de paisagens cársticas. Assim, torna-se possível afirmar que a morfogênese regional é mais complexa do que sugerem os modelos de evolução de longo termo para paisagens do tipo Chapada e, sendo assim, é necessário rever os conceitos teóricos acerca dos processos que envolvem a gênese e evolução dessas formas de relevo. 


\begin{abstract}
:
The Chapada das Mesas, Maranhão/Tocantins, has one of the most reliable landscapes of flat-topped (table) units in Brazil. However, this region has been little studied, especially in terms of its landscape genesis. In this context, this work analyzed the processes that influenced the morfophogenesis of the Chapada das Mesas through the correlation between the lithology, morphostructure and regional drainage system. Therefore, the analysis methods were: (i) morphometric parameters, (ii) measurement of long term $\left({ }^{10} \mathrm{Be}\right)$ denudation processes and, (iii) field works. Based on the analysis made, we concluded that the regional structure directly influenced the setting of the preterit and current drainage, increasing the morphogenesis of this landscape due to internal processes associated with an old underground drainage system that is typical from karst landscape. Thus, it is possible to assert that regional morphogenesis is more complex than suggested by the long-term evolution models for Tablelands type and, therefore, it is necessary to review the theoretical concepts about the processes involved in the genesis and evolution of these landforms.
\end{abstract}

\section{Introdução}

A Chapada das Mesas, localizada na divisa entre as regiões norte e nordeste do Brasil (Maranhão-Tocantins), constitui uma típica paisagem de chapada e tem um importante papel ambiental e ecológico, pelo que, parcialmente, está inserida no Parque Nacional da Chapada das Mesas (PNCM). Contudo, essa região ainda é muito pouco conhecida cientificamente, principalmente no âmbito da geomorfologia e dos processos que culminaram em sua morfogênese e evolução. Tal fato constitui considerável lacuna científica, principalmente em razão da Chapada das Mesas se localizar no contato entre a Bacia Sedimentar do Parnaíba e o Orógeno Brasiliano do Tocantins (Salgado et al., 2015), ou seja, no contato entre diferentes compartimentos geotectônicos e hidrográficos.

As Chapadas são formas de relevo recorrentes no território brasileiro e possuem morfogênese associada a modelos de evolução do relevo caraterizados por desenvolvimento em fases distintas (Martins et al., 2015; Martins \& Salgado, 2016): (1) Formação de superfície sedimentar, metassedimentar ou vulcânica máfica de topografia plana ou quase plana; (2) Incisão da rede de drenagem nessa superfície graças ao aprofundamento do nível de base; (3) Estabelecimento de novo nível de base para a rede de drenagem que incidiu; (4) Individualização dos platôs por meio de recuo lateral das vertentes e; (5) Formação de uma nova superfície erosiva, pontilhada de relevos residuais (tabulares) que preservam em seu topo a topografia da antiga superfície (plana ou quase plana). No entanto, no Brasil foram poucos os estudos científicos que investigaram a morfogênese de paisagens desse tipo. Logo, embora teoricamente as paisagens de chapada sejam bem explicadas, na prática, os modelos elucidativos praticamente nunca foram testados em regiões de Chapada no território brasileiro. Sendo assim, investigações que tentem compreender a morfogênese de paisagens desse tipo no Brasil tornam-se necessárias para o avanço da Geomorfologia nacional.

Tendo por base as premissas acima expostas, pretende-se neste trabalho investigar a morfogênese da paisagem da Chapada das Mesas através da análise integrada de dados morfoestruturais e denudacionais com a rede de drenagem. Objetivou-se discutir não somente a morfogênese da Chapada das Mesas, bem como averiguar a validade do modelo explicativo para formação desse tipo de paisagem.

\section{Caracterização da área de estudo}

A Chapada das Mesas se localiza no interior da unidade geomorfológica denominada pelo IBGE (2006) de Chapadas e Planos do Rio Farinha na divisa entre os estados do Maranhão e Tocantins (Figura 1). Essa região é, em termos de paisagem, caracterizada por um conjunto de formas de relevo exuberante - chapadas que imprime um aspecto cênico de inestimável beleza para esta região (Figura 2). Paralelamente, a área de estudo possui grande importância ecológica, fato esse que, conjugado com a riqueza paisagística, deu origem à criação do Parque Nacional da Chapada das Mesas (PNCM) (BRASIL, decreto de 12 de dezembro de 2005), com aproximadamente 160.000 ha. 

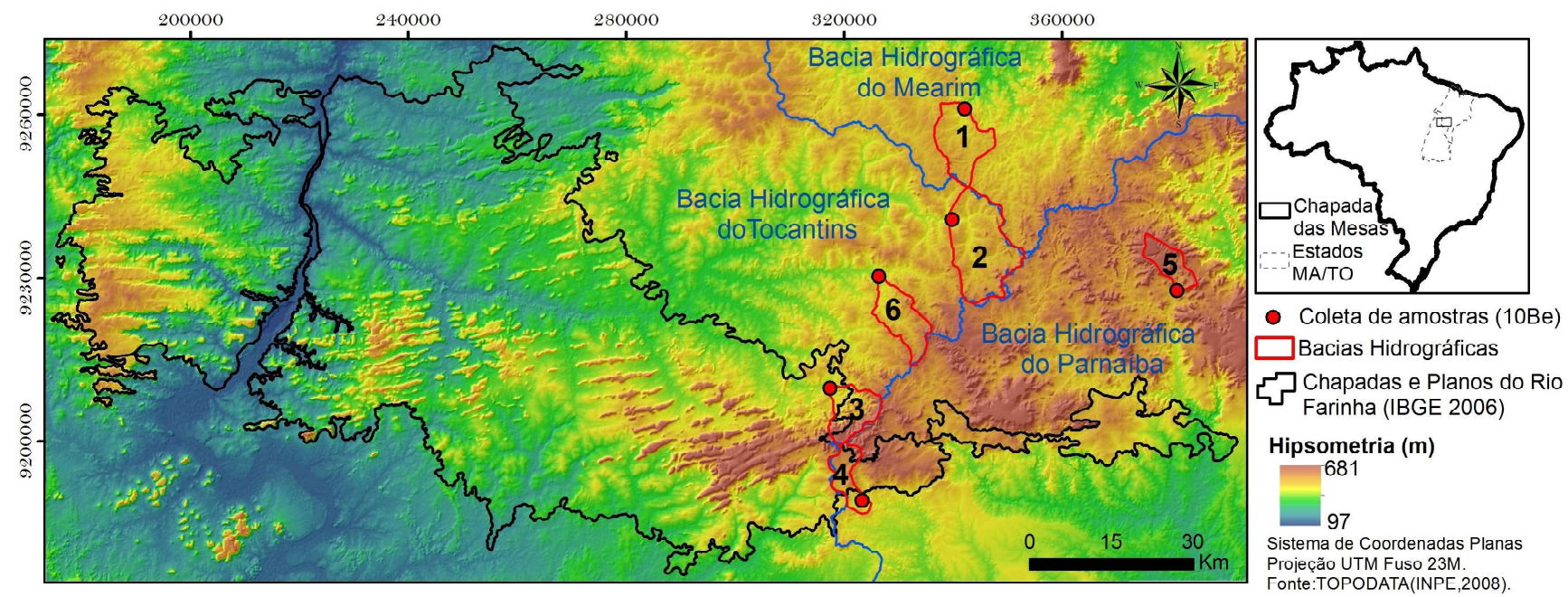

Figura 1 - Localização da área de estudo com ênfase para a Unidade do Relevo Chapadas e Planos do rio Farinha (IBGE, 2006) $e$ localização dos pontos onde foram coletadas amostras de sedimentos para análise do isótopo cosmogênico ${ }^{10}$ Be.

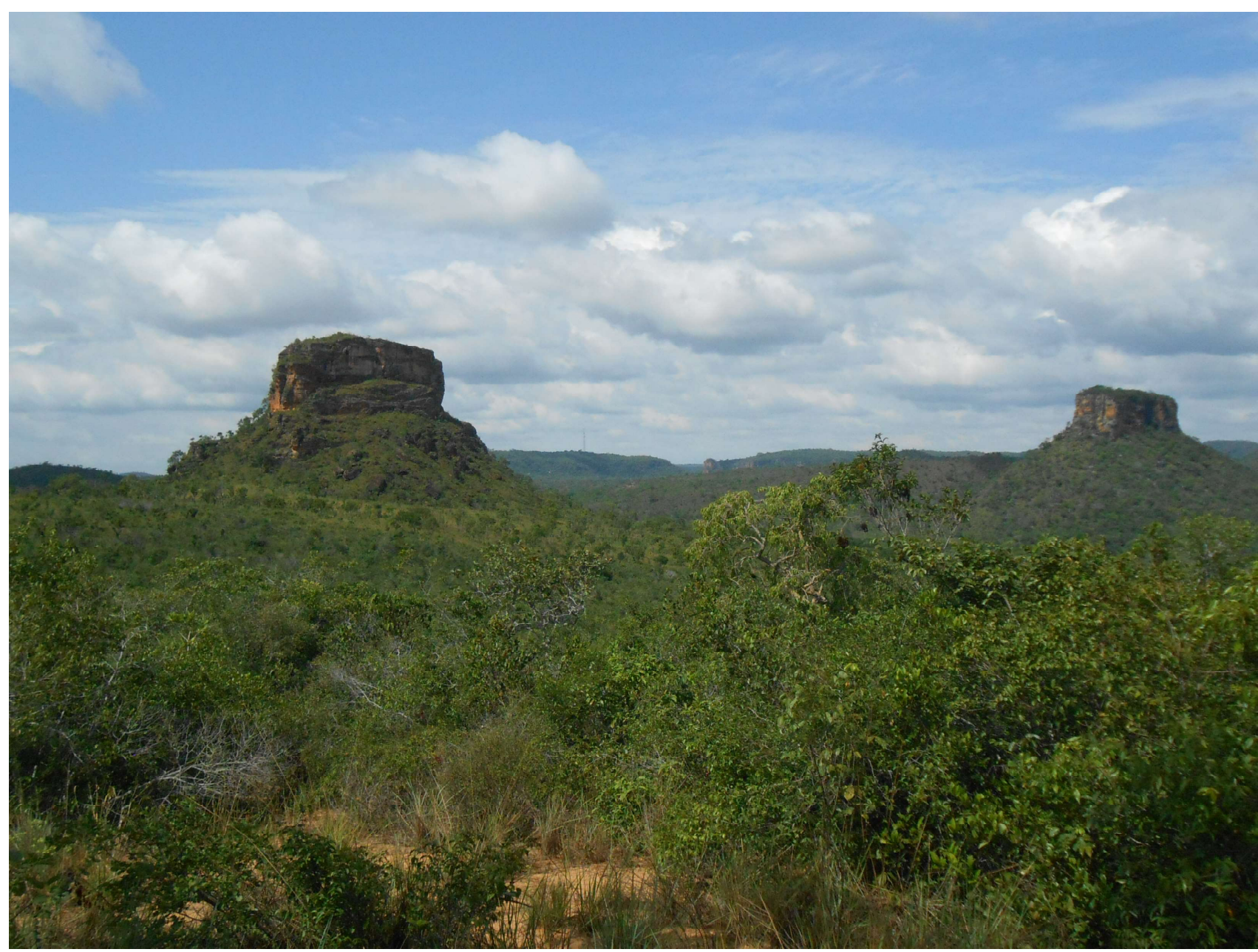

Figura 2 - Paisagem típica da Região da Chapada das Mesas.

Em termos geológicos, a área de estudo se localiza na Bacia Sedimentar do Parnaíba, uma bacia intracratônica de idade Paleozóica, no limite com o antigo Orógeno Tocantins. Possui como substrato litológico uma sucessão de rochas sedimentares e vulcânicas de idade Neoproterozóica-Eopaleozóica (Almeida et al., 1981). $\mathrm{Na}$ área de estudo esse substrato é basicamente arenítico e corresponde às seguintes unidades: (i) às formações 
areníticas meso-paleozóicas Itapecuru, Corda, Grajaú, Sambaíba, Motuca e Pedra de Fogo; (ii) aos basaltos mesozóicos da Formação Mosquito; (iii) aos depósitos detrito-lateríticos terciários; (iv) aos coluviões pleistocênicos, e (v) aos aluviões holocênicos. Vale ressaltar que, nas porções mais elevadas da paisagem, os arenitos são recobertos por depósitos detrítico-lateríticos terciários encouraçados. Este encouraçamento é que sustenta o topo das chapadas e estabelece um nível altimétrico somital para a paisagem regional. Já no sopé das mesas e chapadas acumulam-se os coluviões pleistocênicos compostos por sedimentos conglomeráticos e areno-siltosos laterizados de origem colúvio-aluvial.

O clima regional pode ser caracterizado como Tropical Úmido com altas temperaturas e duas estações bem definidas: invernos secos e verões úmidos (MMA, IBAMA \& PREVFOGO, 2007). A região apresenta importante biodiversidade, que se configura pelo encontro de três importantes biomas brasileiros: Amazônico, Cerrado e Caatinga (Moraes \& Lima, 2007). É drenada em $15.623,7 \mathrm{~km}^{2}$ pela Bacia Hidrográfica do rio Tocantins, em 4.538,75 km² pela Bacia do rio Parnaíba e em menor proporção - 2.005,04 km² - pela Bacia Hidrográfica do rio Mearim.

\section{Materiais e Métodos}

A metodologia desta pesquisa está dividida em cinco eixos principais: (i) análise da litologia e da morfoestrutura via mapeamento temático; (ii) estudo da estruturação e dos padrões da rede hidrográfica; (iii) levantamento de parâmetros morfométricos; (iv) mensuração de processos denudacionais de longo termo via isótopo cosmogênico ${ }^{10} \mathrm{Be}$ e; (v) avaliação qualitativa da paisagem por meio de atividades de campo.

Para o desenvolvimento das análises, foi realizado o levantamento e organização da documentação cartográfica básica que corresponde às oito cartas topográficas do Instituto Brasileiro de Geografia e Estatística (IBGE), na escala de 1:100.000: Wanderlândia, Paranaidji, São Pedro dos Crentes, Fortaleza dos Nogueiras, Babaçulândia, Carolina, Riachão e Canto dos Currais, das quais foram extraídos os dados de rede de drenagem a partir de vetorização manual. Na caracterização e análise litoestrutural foram utilizados os planos de informação temáticos (geologia e lineamentos estruturais) da base vetorial da Amazônia Legal, adquiridos por meio do acervo do IBGE (2006). Os parâmetros mor- fométricos foram calculados a partir do Modelo Digital de Elevação, Projeto TOPODATA-INPE (Valeriano \& Rosseti, 2012) com resolução espacial de $30 \mathrm{~m}$.

A partir da organização da base cartográfica da área de estudo, foram realizadas as análises espaciais com ferramentas específicas dos Softwares ArcGIS 10.1, SPRING 5.2.1 e MATLAB, onde foram gerados os respectivos parâmetros: (i) densidade de drenagem (Dd); (ii) densidade de lineamentos (Dl) (Vilela \& Matos, 1975); (iii) Fator de Assimetria da Bacia de Drenagem (FABD) (Hare \& Gardner, 1985); (iv) Fator de Assimetria Topográfica Transversal (FSTT) (Cox ,1994); e (v) perfis topográficos.

$\mathrm{Na}$ etapa de campo, foram realizadas as análises qualitativas da paisagem regional e foram coletadas amostras de sedimentos aluviais em seis bacias hidrográficas (Figura 1). Os critérios para a amostragem consideraram os respectivos aspectos: (i) mínima perturbação antrópica para que as amostras representem a dinâmica geomorfológica da área de estudo; (ii) localização dos pontos na área core da unidade geomorfológica de domínio de chapadas e, na área de entorno desta unidade, abrangendo as três principais bacias hidrográficas que drenam a região; (iii) seleção de bacias com substrato rochoso representativo das principais formações litológicas da área e; (iv) tamanho das bacias entre 40 e 180 km$^{2}$, conforme adotado para mensuração de taxas de denudação via isótopo cosmogênico (Brown et al., 1995; Granger et al., 1996).

As taxas de denudação de longo termo $\left({ }^{10} \mathrm{Be}\right)$ foram quantificadas a partir das seis amostras de sedimentos aluviais. A mensuração de processos erosivos via isótopo cosmogênico ${ }^{10} \mathrm{Be}$ tem sido um dos mais usados nos estudos geomorfológicos para análise da evolução da paisagem. Os isótopos estáveis de ${ }^{10} \mathrm{Be}$ são formados por meio de raios cósmicos que atingem a superfície terrestre e interagem com materiais litosféricos ricos em quartzo (Lal, 1991). Assim, a partir da quantificação do acúmulo de ${ }^{10} \mathrm{Be}$ em sedimentos ricos em quartzo, é possível estimar a taxa de denudação média de uma bacia em até 1,38 Ma, tempo que corresponde à meia-vida do ${ }^{10} \mathrm{Be}$.

O processo de extração e purificação química do quartzo das amostras coletadas foi realizado na França, sob a supervisão da equipe do Laboratório Nacional de Nuclídeos Cosmogênicos (LN2C) do Centro Europeu de Pesquisa e Ensino em Geociências e Meio Ambiente 
(CEREGE). Após o tratamento laboratorial, as amostras foram encaminhadas para um espectômetro de aceleração de massa ASTER, onde foi realizada a medição da concentração de átomos de ${ }^{10} \mathrm{Be}$. A partir dos resultados, procedeu-se ao cálculo da taxa de denudação, por meio da seguinte equação:

$$
\begin{gathered}
C_{(x, \varepsilon, t)}=\frac{P_{\text {spall. }}}{\frac{\varepsilon}{\Lambda_{n}}+\lambda} \cdot e^{-\frac{x}{\Lambda_{n}}}\left[1-\exp \left\{-t\left(\frac{\varepsilon}{\Lambda_{n}}+\lambda\right)\right\}+\right. \\
\frac{\frac{\mathrm{P}_{\mu_{\_} \text {slow }}}{\frac{\varepsilon}{\Lambda_{\mu s}}+\lambda} \cdot e^{-\frac{x}{\Lambda_{\mu s}}}\left[1-\exp \left\{-t\left(\frac{\varepsilon}{\Lambda_{\mu s}}+\lambda\right)\right\}\right]+}{\frac{\mathrm{P}_{\mu_{\_} \text {fast }}}{\frac{\varepsilon}{\Lambda_{\mu f}}+\lambda} \cdot e^{-\frac{x}{\Lambda_{\mu f}}}\left[1-\exp \left\{-t\left(\frac{\varepsilon}{\Lambda_{\mu f}}+\lambda\right)\right\}\right]}
\end{gathered}
$$

onde $\mathbf{C}$ é a concentração de nuclídeos; $\mathbf{P}_{\mathbf{0}}$ (átomos. $\mathrm{g}^{-1}$. ano ${ }^{-1}$ ) é a produção total de ${ }^{10} \mathrm{Be}$ na superfície; $\Lambda_{\mathrm{n},} \Lambda_{\mu \mathrm{s}}$, $\Lambda_{\mu \mathrm{f}}$ ão os respectivos fatores de atenuação dos nêutrons, dos muons lentos e dos muons rápidos $\mathrm{em} \mathrm{g} . \mathrm{cm}^{-2}$ (Braucher et al., 2011); $\mathbf{P}_{\mathbf{n}} \mathbf{P}_{\mu \mathrm{s},} \mathbf{P}_{\mu \mathrm{f}}\left(\mathrm{P}_{\mathrm{n}} \mathrm{P}_{\mu \mathrm{s}} \mathrm{P}_{\mu \mathrm{f}}=1\right.$ ) são as contribuições relativas das produções dessas partículas na produção total $\mathrm{P}_{0}$ de ${ }^{10} \mathrm{Be}$; $\varepsilon$ é a taxa de denudação $\left(\mathrm{g} . \mathrm{cm}^{-2} \cdot \mathrm{a}^{-1}\right) ; \lambda$ é a constante de desintegração radioativa do ${ }^{10} \mathrm{Be}\left(\mathrm{T}_{1 / 2}=1,38.10^{6}\right.$ anos); $\varepsilon$ é a taxa de denudação $(\mathrm{m} / \mathrm{Ma}) ; \rho$ corresponde à densidade do arenito $(2.35$ g. $\left.\mathrm{cm}^{-3}\right)$; e t é tempo de exposição da rocha.

Por fim, o trabalho de campo visou não apenas a coleta de sedimentos - granulometria areia - para análise laboratorial visando a mensuração do isótopo cosmogênico ${ }^{10} \mathrm{Be}$, mas também objetivou realizar uma análise qualitativa da paisagem com ênfase para observação das formas que compõe o relevo regional.

\section{Resultados}

Na região da Chapada das Mesas, a Dd (densidade de drenagem) tem um valor de $0,84 \mathrm{~km} / \mathrm{km}^{2}$, mas, ao considerar apenas o limite da unidade de relevo Chapadas e Planos do Rio Farinha que se localiza principalmente na porção centro-ocidental da área de estudo (Figura 3), este índice é ainda menor, com um valor de $0,76 \mathrm{~km} / \mathrm{km}^{2}$. Ao contrário, a Dl (densidade de lineamentos) é maior dentro dessa unidade geomorfológica quando comparada com a área externa (Figura 4). Os lineamentos estruturais - falhas e fraturas - possuem direção preferencial para E-W com deflexão de NE-SW, variando em torno de N80E e, em menor quantidade, entre N70E e N60E (Figura 5). Já as chapadas também estão dispostas no sentido NE-SW, variando entre N70E e N80E para frequência absoluta e comprimento absoluto (Figura 6).

A rede de drenagem possui direção diversificada, com frequência absoluta, principalmente, em N-S, com destaque para NE-SW em N10E, N30E e N40E. Já o comprimento absoluto apresenta duas direções preferenciais, a NW-SE em N80W e a NE-SW em N60E (Figura 7a). Sabendo-se que os cursos de menor ordem são mais susceptíveis a seguir as mudanças no terreno, foram analisadas separadamente as drenagens de primeira e segunda ordem (figuras $7 b$ e 7c). Para os canais de primeira ordem, a frequência absoluta demonstra direção majoritária de N-S, em N10W, seguido em menor quantidade para NE-SW em N40E e E-W em N80E. Entretanto, quando analisado o gráfico de comprimento absoluto, esses valores são maiores de E-W, em N80E, seguidos pela direção NE-SW em N50E, N60E e N40E (Figura 7b). Já para os canais de segunda ordem, na frequência absoluta e no comprimento absoluto, possuem direção NE-SW em N70E (Figuras 7c), assim como a direção da disposição das chapadas (Figura 6) e dos lineamentos estruturais (Figura 5).

A disposição geral das chapadas e da rede de drenagem ainda pode ser analisada a partir de três perfis topográficos regionais (Figura 8). Os perfis 1 e 2 estão próximos ao eixo $\mathrm{N}-\mathrm{S}$, enquanto o perfil 3 corta toda a unidade de relevo Chapadas e Planos do Rio Farinha, de E-W. Os perfis mostram que as chapadas estão, majoritariamente, cortadas por drenagens de $1^{\mathrm{a}}$ e $2^{\mathrm{a}}$ ordens. No que se refere à análise do FSTT (Fator de Assimetria Topográfica Transversal), nos afluentes do rio Tocantins, não houve elevadas migrações, pois as mesmas permaneceram entre $0,02 \mathrm{e} 0,21$ (Tabela 1 ). Isto sugere que não há um controle neotectônico evidente na região. Quanto ao FABD (Fator de Assimetria da Bacia de Drenagem), dentre as 13 sub-bacias hidrográficas analisadas, $30,76 \%$ indicaram pouco ou nenhum basculamento (FABD entre 45 e 55), 38,46\% sugeriram migração média para a margem direita (FABD entre 55 e 65 ) e $30,76 \%$ sugeriram migração média para a esquerda (FABD entre $45 \mathrm{e}<35$ ) (Tabela 1). 

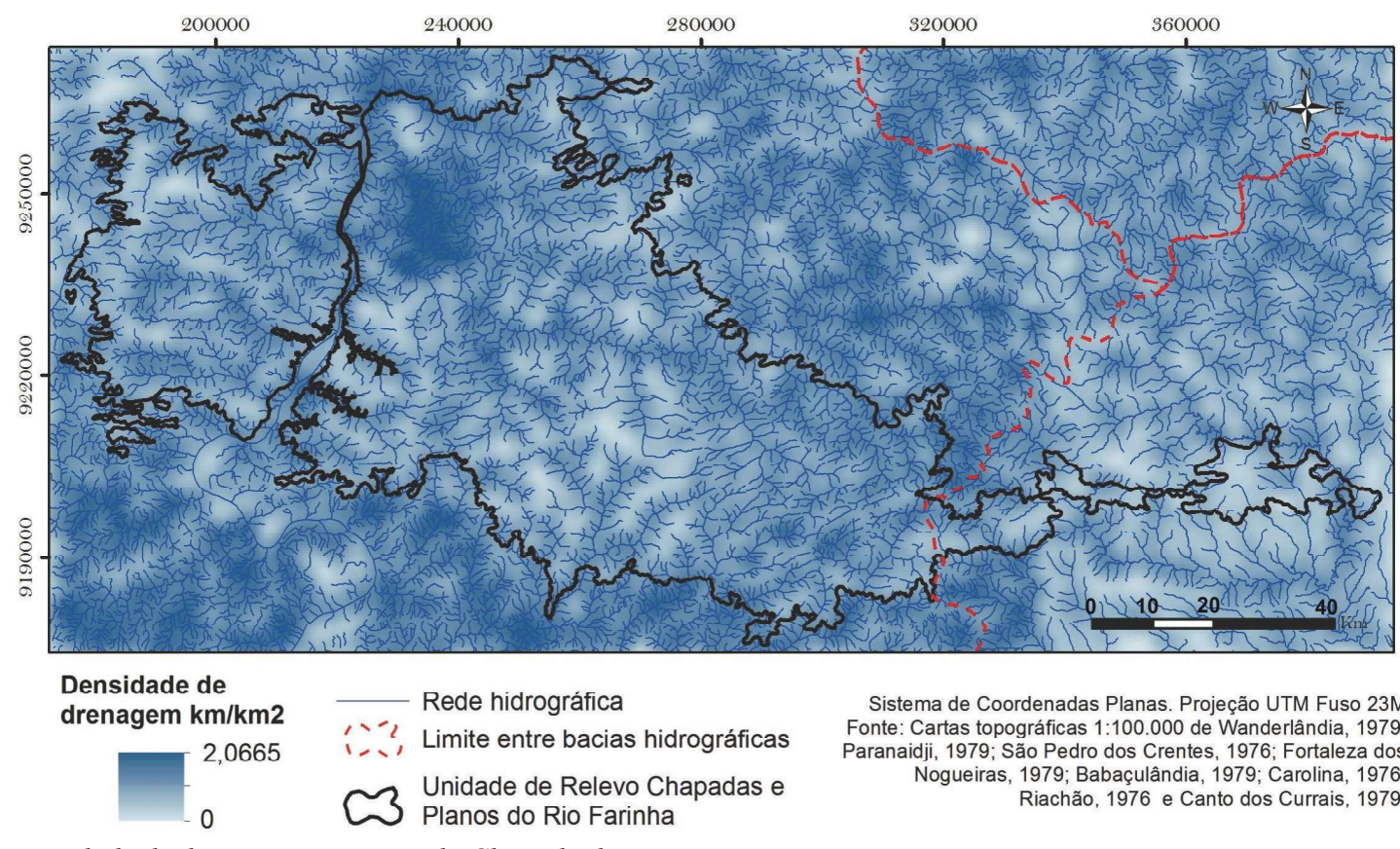

Sistema de Coordenadas Planas. Projeção UTM Fuso 23M. Fonte: Cartas topográficas 1:100.000 de Wanderlândia, 1979; Paranaidji, 1979: São Pedro dos Crentes, 1976; Fortaleza dos Nogueiras, 1979; Babaçulândia, 1979; Carolina, 1976 Riachão, 1976 e Canto dos Currais, 1979.

Figura 3 - Densidade de drenagem na região da Chapada das Mesas.

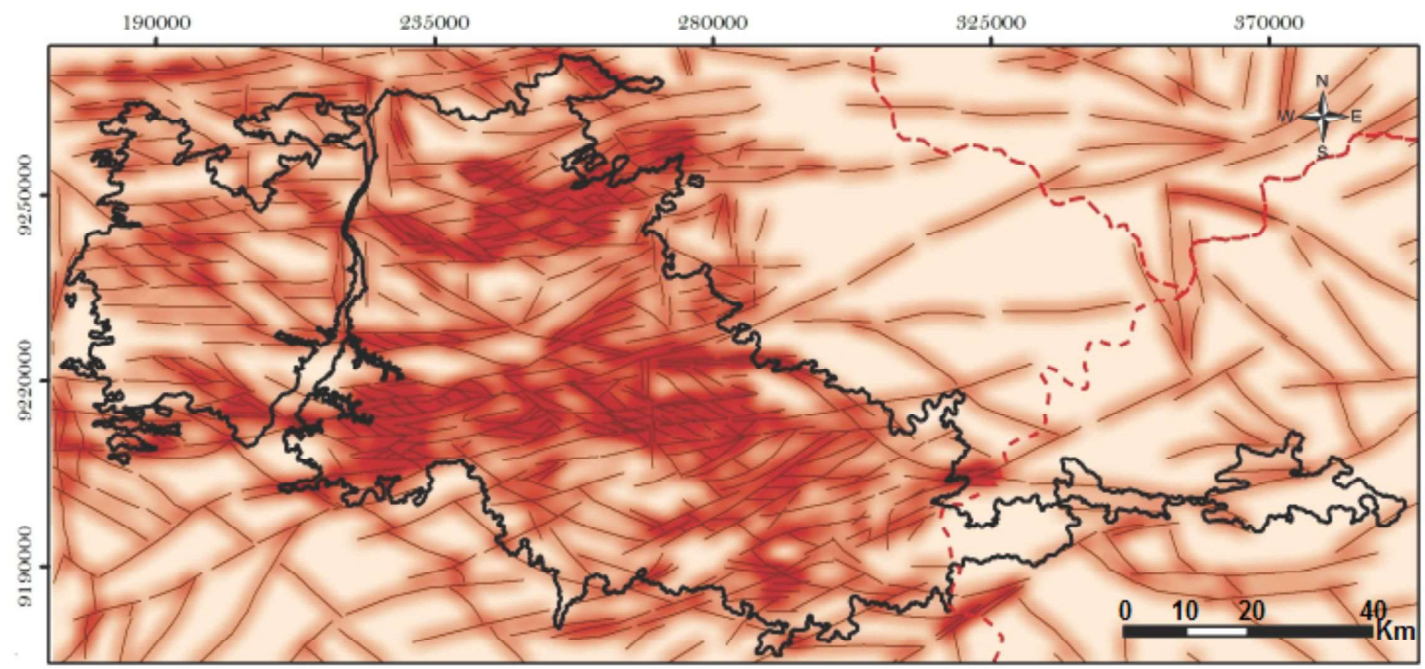

Densidade de lineamentos $\cong \because$, Limite entre bacias hidrográficas

$\begin{array}{lll}\text { Maior densidade } & 3 \begin{array}{l}\text { Unidade de Relevo Chapadas e } \\ \text { Planos do Rio Farinha }\end{array} & \begin{array}{l}\text { Sistema de coordenadas UTM. WGS, 1984, 23S. } \\ \text { Menor densidade }\end{array} \quad \text { Lineamentos (Falhas e Fraturas) } \\ \text { Fonte: IBGE. }\end{array}$

Figura 4 - Densidade de lineamentos na região da Chapada das Mesas.

\section{Frequência Absoluta}

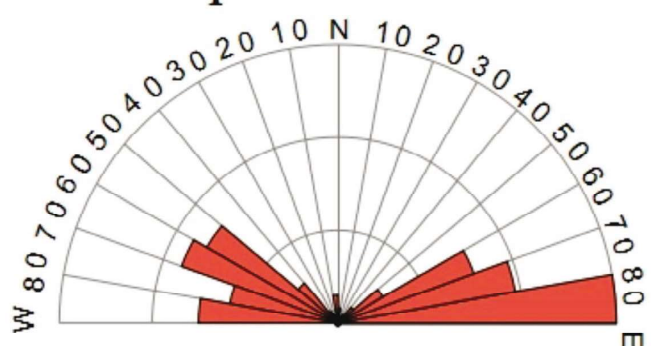

\section{Comprimento Absoluto}

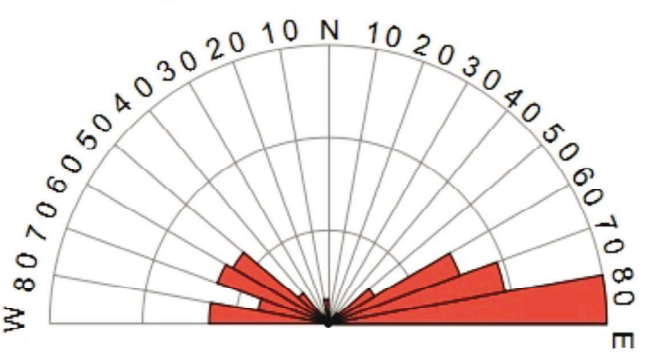

Figura 5 - Diagrama de rosetas dos lineamentos morfoestruturais em frequência absoluta $e$ comprimento absoluto de Falhas e Fraturas na Região da Chapada das Mesas. 


\section{Frequência absoluta}

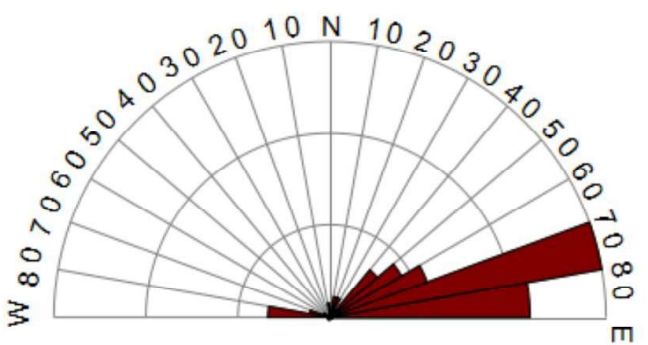

\section{Comprimento absoluto}

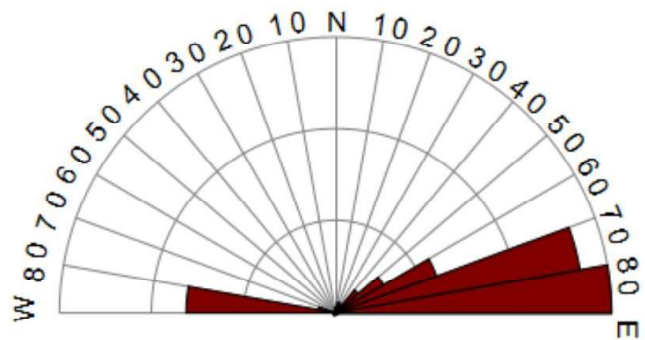

Figura 6 - Diagrama de rosetas em frequência absoluta $e$ comprimento absoluto referente a direção das mesas dentro da Unidade Chapadas e Planos do Rio Farinha.

\section{Frequência Absoluta}

a) Canais de todas as ordens

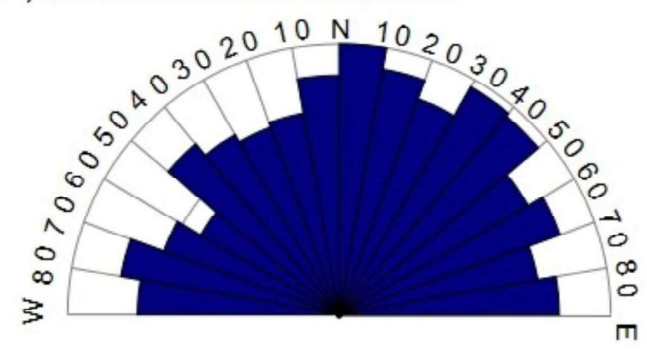

b) Canais de primeira ordem

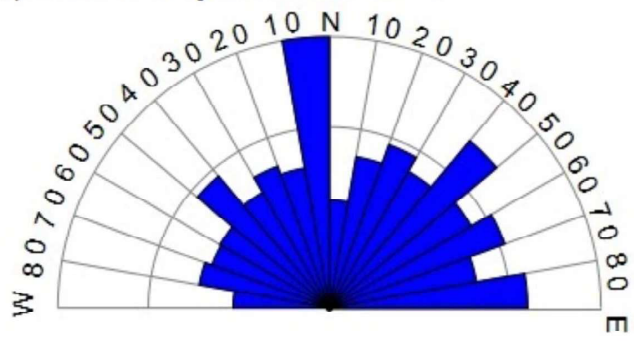

\section{Comprimento Absoluto}

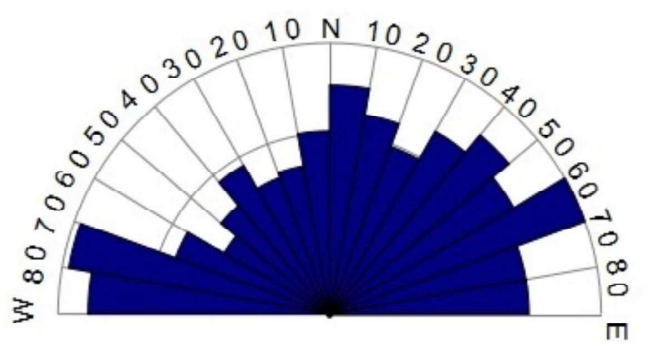

c) Canais de segunda ordem
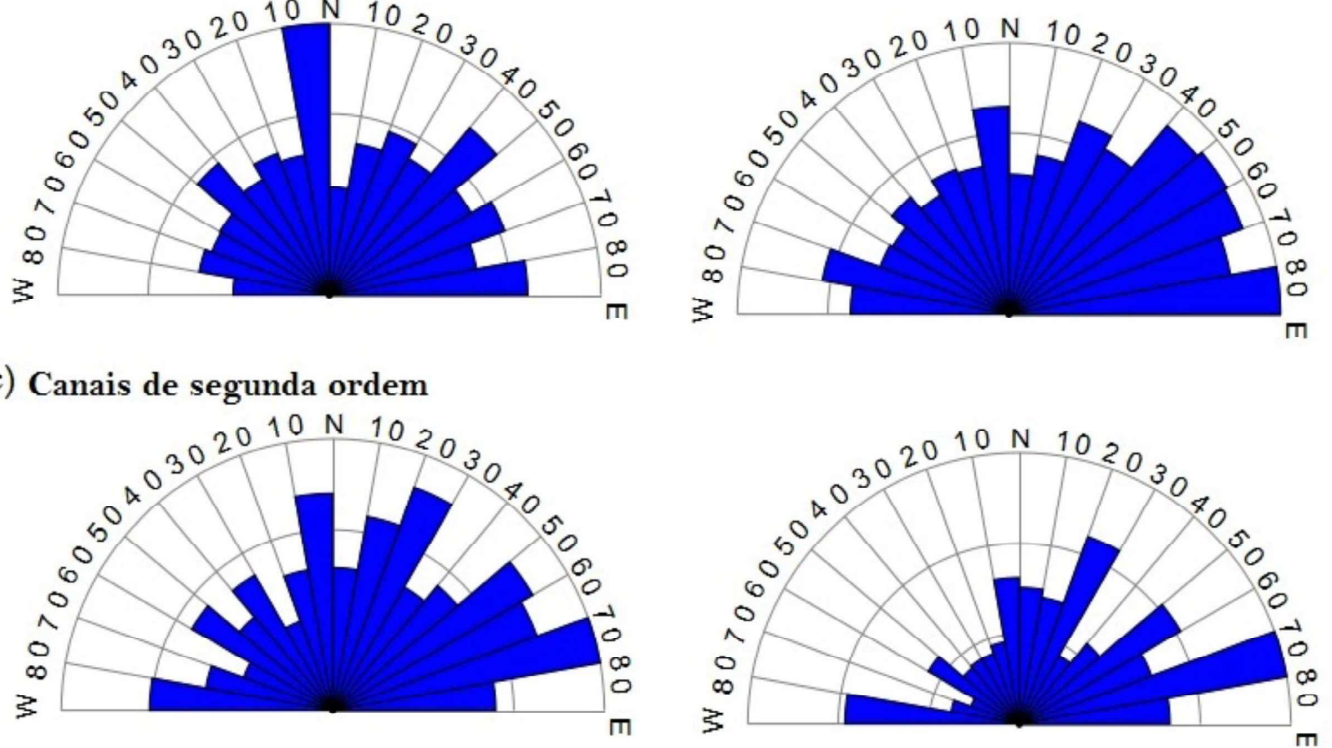

Figura 7 - Diagrama de rosetas com frequência absoluta e comprimento absoluto da rede de drenagem da região de estudo: (a) drenagem de todas as ordens, (b) de primeira ordem e (c) de segunda ordem.

Em termos de denudação de longo-termo $\left({ }^{10} \mathrm{Be}\right)$, a mesma se apresentou extremamente variável na área de estudo (Tabela 2). Essa variação foi extrema, visto que foram mensuradas taxas medianas - na faixa de 12 metros por milhão de anos - paralelamente a outras muito mais elevadas e que superaram os 60 metros por milhão de anos (Tabela 2). Sendo assim, as maiores taxas erosivas mensuradas na área superam, inclusive, a maior parte das taxas já registradas nas faces mais escarpadas da Serra do Mar (Salgado et al., 2013; 2016; Gonzalez et al., 2016), área onde foram, até ao presente momento, mensuradas as mais altas taxas erosivas do Brasil via ${ }^{10} \mathrm{Be}$. 

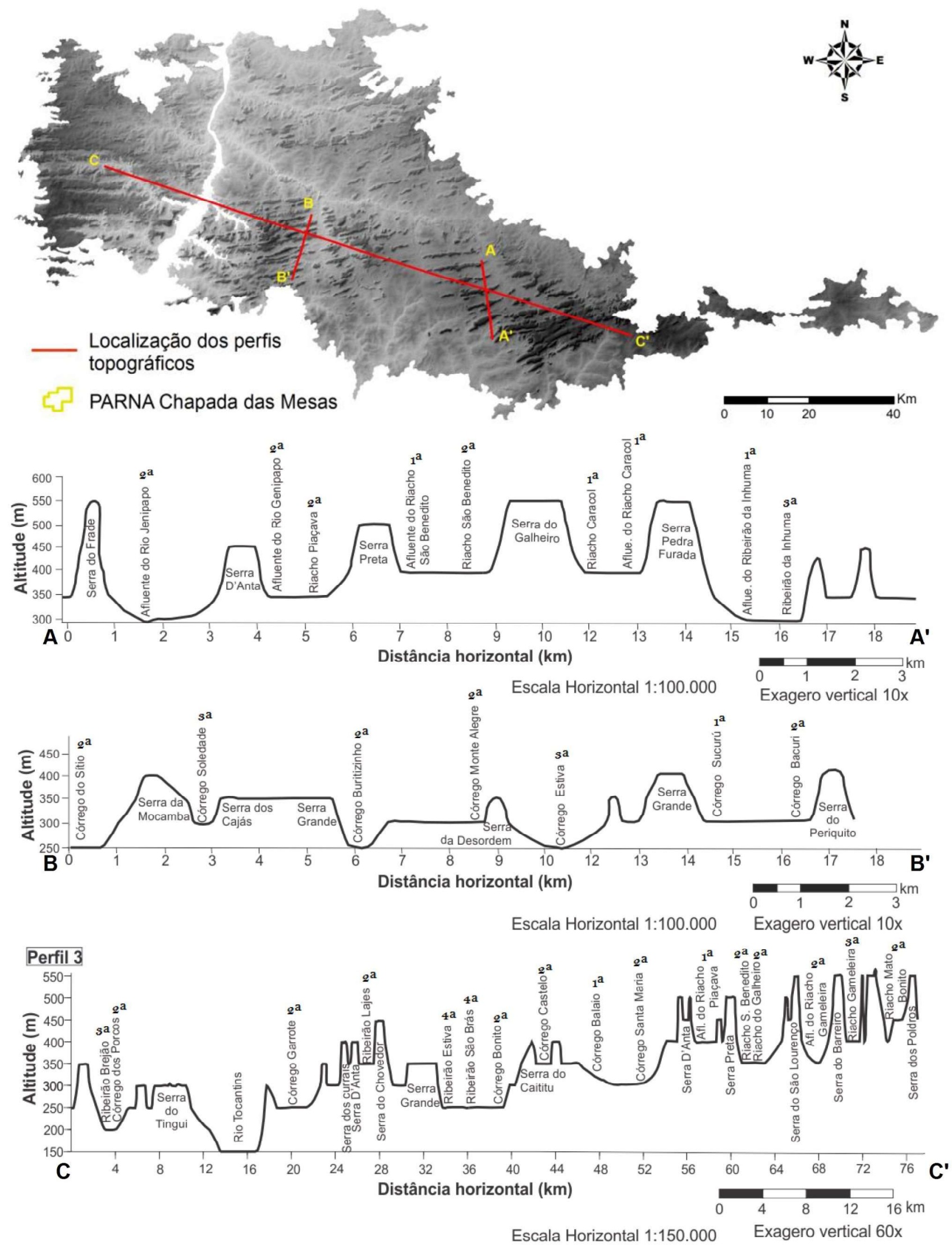

Figura 8 - Perfis topográficos na área de estudo com a disposição das mesas e da drenagem com suas respectivas ordens de canal segundo Strahler (1952). 
Tabela 1: Índices de Fator de Assimetria da Bacia de Drenagem (FABD) e Fator de Assimetria Topográfica Transversal (FSTT), incluindo média (x) e desvio padrão (s), em sub-bacias de $3^{\circ}$ e $4^{\circ}$ ordem fluvial da área analisada.

\begin{tabular}{l|c|c|c}
\hline Bacia Hidrográfica & \multicolumn{2}{c}{ FSTT } & FABD \\
\hline Rio Brejão & 0,18 & 0,21 & 33,07 \\
\hline Riacho Jenipapo & 0,05 & 0,07 & 34,99 \\
\hline Ribeirão Corrente & 0,18 & 0,14 & 47,09 \\
\hline Ribeirão Estiva & 0,07 & 0,07 & 62,37 \\
\hline Ribeirão São José & 0,14 & 0,08 & 59,14 \\
\hline Ribeirão Pedra Caída & 0,07 & 0,06 & 44,09 \\
\hline Ribeirão Taboca & 0,12 & 0,07 & 46,88 \\
\hline Ribeirão Brejão & 0,08 & 0,11 & 55,29 \\
\hline Ribeirão Campo Alegre & 0,07 & 0,07 & 55,29 \\
\hline Rio Feio & 0,08 & 0,07 & 37,41 \\
\hline Riacho Velho & 0,13 & 0,08 & 45,77 \\
\hline Ribeirão Galheiro & 0,05 & 0,02 & 50,76 \\
\hline Ribeirão Mata Verde & 0,12 & 0,1 & 63,07 \\
\hline
\end{tabular}

Tabela 2: Taxas de denudação de longo-termo ${ }^{10} \mathrm{Be}$ mensuradas na região da Chapada das Mesas

\begin{tabular}{|c|c|c|c|c|c|c|}
\hline $\begin{array}{l}\text { Ponto de } \\
\text { Amostra }\end{array}$ & $\begin{array}{c}\text { Bacia } \\
\text { Hidrográfica } \\
\text { (Afluente) }\end{array}$ & $\begin{array}{c}\text { Área da } \\
\text { sub-bacia } \\
\text { amostrada } \\
\left(\mathrm{km}^{2}\right)\end{array}$ & $\begin{array}{c}\text { Longitude e } \\
\text { Latitude } \\
\text { (graus decimais) }\end{array}$ & $\begin{array}{c}\text { Concentração } \\
\text { de átomos de }{ }^{10} \mathrm{Be} \\
\left(\text { átomos } \mathrm{g}^{-1}\right)^{*} 10^{5}\end{array}$ & $\begin{array}{c}\text { Taxa de } \\
\text { denudação } \\
{ }^{10} \mathrm{Be} \\
(\mathrm{m} / \mathrm{Ma})\end{array}$ & $\begin{array}{l}\text { Tempo de } \\
\text { Integração } \\
\text { (anos) }\end{array}$ \\
\hline 1 & $\begin{array}{c}\text { Mearim } \\
\text { (Grajauzinho) }\end{array}$ & 96,7 & $\begin{array}{l}-46,428285 \\
-6,683201\end{array}$ & $0,41 \pm 0,02$ & $68,9 \pm 2,72$ & 9.217 \\
\hline 2 & $\begin{array}{l}\text { Tocantins } \\
\text { (Farinha) }\end{array}$ & 180,1 & $\begin{array}{c}-46,449946 \\
-6,866661\end{array}$ & $2,02 \pm 0,06$ & $12,8 \pm 0,41$ & 48.601 \\
\hline 3 & $\begin{array}{l}\text { Tocantins } \\
\text { (Fariazinha) }\end{array}$ & 72,2 & $\begin{array}{l}-46,65362 \\
-7,146798\end{array}$ & $0,49 \pm 0,02$ & $60,0 \pm 2,15$ & 10.584 \\
\hline 4 & $\begin{array}{l}\text { Parnaíba } \\
\text { (Frutuoso) }\end{array}$ & 42,7 & $\begin{array}{l}-46,601031 \\
-7,332999\end{array}$ & $2,08 \pm 0,07$ & $12,6 \pm 0,40$ & 49.232 \\
\hline 5 & $\begin{array}{l}\text { Parnaíba } \\
\text { (Fundo) }\end{array}$ & 48,4 & $\begin{array}{c}-46,077306 \\
-6,98585\end{array}$ & $1,21 \pm 0,10$ & $23,9 \pm 2,06$ & 26.310 \\
\hline 6 & $\begin{array}{l}\text { Tocantins } \\
\text { (Conceição) }\end{array}$ & 81,5 & $\begin{array}{c}-46,571707 \\
-6,9615\end{array}$ & $1,48 \pm 0,05$ & $18,0 \pm 0,57$ & 34.755 \\
\hline
\end{tabular}

Por fim, a análise qualitativa da paisagem realizada em campo, reafirmou que o relevo regional é caracterizado principalmente pela existência de Chapadas. Estas possuem topo em cota altimétrica semelhante, mas área de superfície muito variável. Entretanto, além das formas de relevo do tipo Chapada, o que mais cha- ma a atenção na paisagem regional é a ocorrência de formas típicas de um paleocarste em arenito como, por exemplo, arcos em topos de morro, pequenas cavidades, cânions que parecem ter sua gênese associada a queda do teto de uma caverna, paleosumidouros, sumidouros e ressurgências fluviais (Figura 9). 

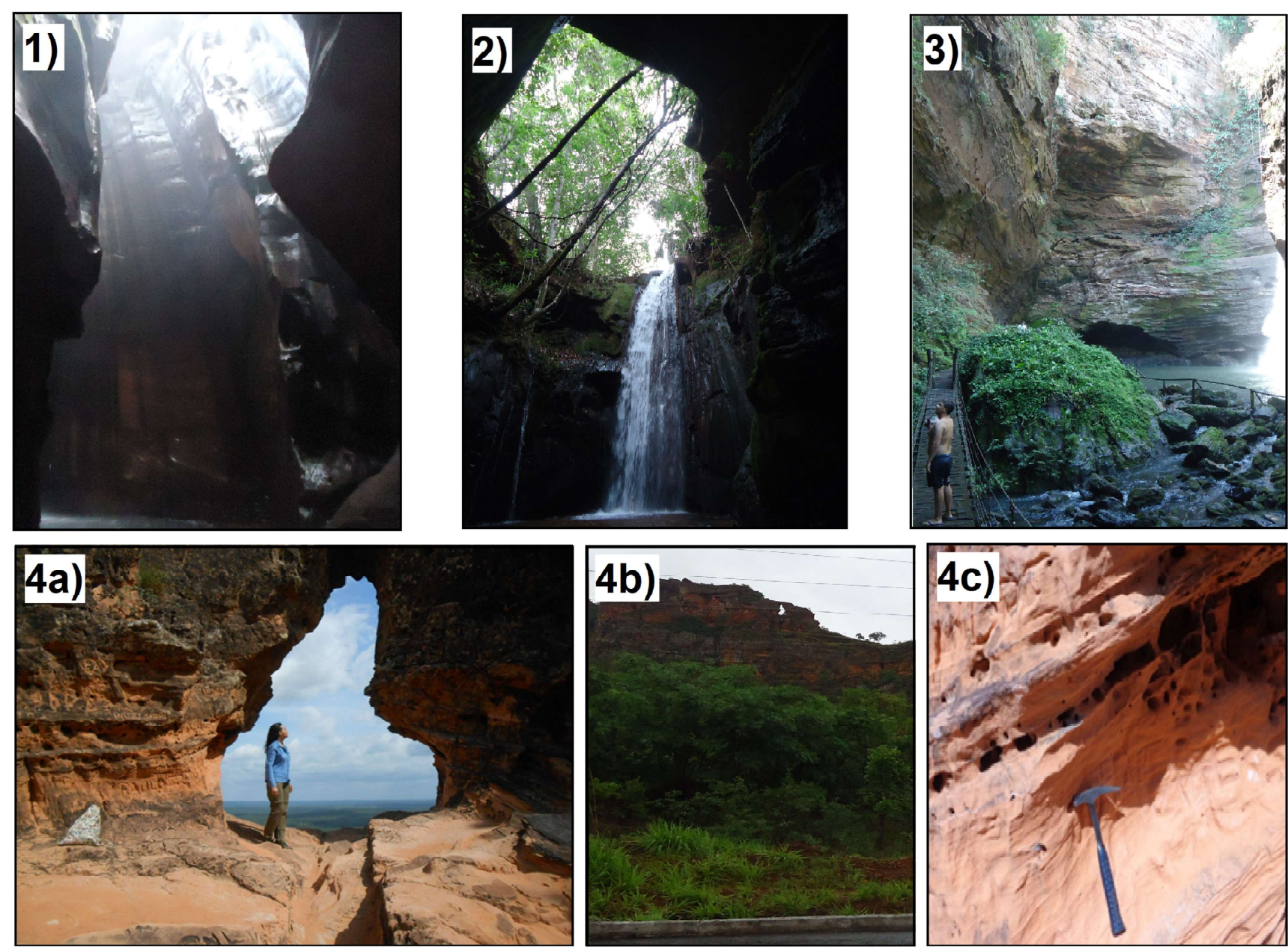

Figura 9 - Formas cársticas na região da Chapada das Mesas, MA/TO. (1) Cachoeira do Santuário e (2) Cachoeira da Caverna; (3) Cânion e caverna da Cachoeira de Santa Bárbara; (4a e b) Arco da Pedra Caída; (4c) Ductos em diversos diâmetros na rocha que compõe o portal da Pedra Caída.

\section{Discussões}

A região da Chapada das Mesas tem Dd baixa ou regular baixa, sendo esse índice ainda menor quando se analisa apenas a unidade de relevo Chapadas e Planos do Rio Farinha. De acordo com Barreto et al. (2001), a Dd é uma expressão da intensidade do escoamento superficial e, portanto, quanto menor a densidade de drenagem, menor o escoamento superficial e maior a infiltração. Essa baixa taxa regional da Dd pode ser considerada normal, pois o principal substrato da região é o arenito, rocha muito porosa. Entretanto, chama a atenção que a relação entre Dd e Dl é claramente inversamente proporcional (figuras 3 e 4). Ou seja: quanto maior a ocorrência de lineamentos (Dl), maior a porosidade secundária (estrutural) e por isso maior a infiltração de água, diminuindo assim a drenagem superficial (Dd). Há uma exceção a essa lógica no extremo norte da unidade, que apresenta uma porção com elevada Dd e, ao mesmo tempo, elevada concentração de lineamentos (figuras 3 e 4). No entanto, este fato pode ser explicado em razão de que esta área tem sua altitude muito próxima à do nível de base regional (Rio Tocantins), o que não favorece a infiltração da água, mas sim, seu escoamento pela superfície.

A rede de drenagem apresenta direção muito diversificada. Isto é próprio de ambientes de clima tropical úmido e raramente coincide com o direcionamento dos lineamentos estruturais (figuras 5 e 7). Os dados de FSTT e FABD também dão suporte a essa interpretação, pois as sub-bacias analisadas de $3^{\circ} \mathrm{e} 4^{\circ}$ ordens não possuem controle neotectônico evidente e, tampouco, forte migração de seus canais (Tabela 1). 
Ao contrário dessas sub-bacias, a estrutura tende a controlar de forma mais expressiva os cursos de primeira e segunda ordem, os quais apresentam, em diversas porções da área, padrão paralelo de drenagem (figuras 5 e 7). $O$ posicionamento similar entre a direção dos lineamentos estruturais, da drenagem - principalmente de segunda ordem - e das chapadas (figuras 5, 6 e 7) indica influência direta da estrutura geológica nos canais de menor ordem hierárquica e na dissecação do relevo. Por conseguinte, indica de forma inequívoca que a estrutura influencia diretamente o arranjo espacial das chapadas. Logo, como visualizado nas rosetas dos canais de $1^{\mathrm{a}} \mathrm{e} 2^{\mathrm{a}}$ ordem e nos perfis topográficos (figuras 7 e 8), estes seguem os lineamentos e abrem os cânions individualizando, assim, as chapadas.

A imensa variação nas taxas de denudação registradas que vão de 12,6 até $68,9 \mathrm{~m} / \mathrm{Ma}$ (Tabela 2), bem como o fato de algumas delas terem alcançado patamares maiores do que quase todas as taxas já mensuradas na escarpada e elevada Serra do Mar, não podem ser explicados apenas pelo modelo tradicional de gênese das Chapadas (Martins \& Salgado, 2016). Inclusive em razão de que as taxas mais elevadas são incompatíveis com as mais baixas mensuradas na mesma região e em bacias hidrográficas vizinhas, bem como são também inconciliáveis com os índices de FSTT e de FABD e com a morfologia da paisagem regional que não é composta por montanhas e serras escarpadas, mas, sim, por Chapadas.

Neste ponto há de se considerar que um sedimento que nunca foi influenciado pela radiação cósmica, ou seja, um que nunca esteve em condições de superfície, não apresenta em seu interior o isótopo cosmogênico ${ }^{10} \mathrm{Be}$, pois é o bombardeamento natural dessa radiação sobre as rochas e sedimentos que produz, no interior dos minerais, esse isótopo. No outro extremo, um sedimento que tenha sido lentamente erodido e transportado, apresentará quantidades elevadas de ${ }^{10} \mathrm{Be}$, visto que permaneceu muito tempo sendo influenciado pela radiação cósmica. Logo, sedimentos com muito ${ }^{10} \mathrm{Be}$ significam taxas de denudação baixas pois permaneceram um bom tempo em condições de superfície e foram, portanto, muito bombardeados pela radiação cósmica. Já aqueles com pouco ${ }^{10} \mathrm{Be}$, são oriundos de taxas de denudação altas, pois foram rapidamente erodidos e transportados e por isso permaneceram pouco tempo sob ação da radiação cósmica. Neste contexto, elevadas taxas de denudação significam que minerais que nunca estiveram em condições superficiais, alcançaram a mesma de forma muito rápida. Em ambientes com baixa interferência antrópica, isso só pode ocorrer se as amostras são oriundas de áreas com soerguimento tectônico pronunciado - com suas consequentes elevadas taxas de denudação - ou se os sedimentos chegaram a superfície por terem sido ejetados de cavernas ou pelo colapso do teto das mesmas.

Considerando-se a morfologia da paisagem chapadas - tal fato leva a crer que a única forma de algumas bacias hidrográficas apresentarem taxas de denudação tão elevadas (Tabela 2) é a de muitos dos seus sedimentos terem alcançado a superfície de forma abrupta independente do processo erosivo tradicional. Neste contexto, apenas a ejeção de sedimentos subterrâneos em ressurgências fluviais ou o desabamento do teto de cavernas permitiria que sedimentos localizados muitos metros em subsuperfície alcançassem abruptamente a superfície. Logo, as formas cársticas verificadas na paisagem regional (Figura 9) são indícios imprescindíveis à compreensão das elevadas taxas denudacionais mensuradas (Tabela 2), bem como ao entendimento da morfogênese regional. Na verdade elas constituem pequenas evidências de um sistema muito maior e ainda desconhecido que é essencial para a compreensão da evolução do relevo da Chapada das Mesas. Isso levanta a hipótese de que a drenagem que acompanha as falhas é, em grande parte, subsuperficial e forma um sistema subterrâneo que somente é exposto quando, em estágio mais avançado, seu teto entra em colapso e origina esses tributários formando cânions e cachoeiras. Desta forma, a morfogênese da Chapada das Mesas parece estar associada a um processo de dissecação do relevo que, graças ao trabalho de cursos fluviais de primeira e segunda ordem, estes escoando na superfície ou em subsuperfície, recortam a área e isolam as chapadas umas das outras (Figura 10). Logo, a paisagem regional possui gênese muito mais complexa do que o modelo tradicional de formação de chapadas previa (Martins \& Salgado, 2016). Neste caso, pode ter gênese, majoritariamente, associada a processos típicos do carste (Figura 10). 


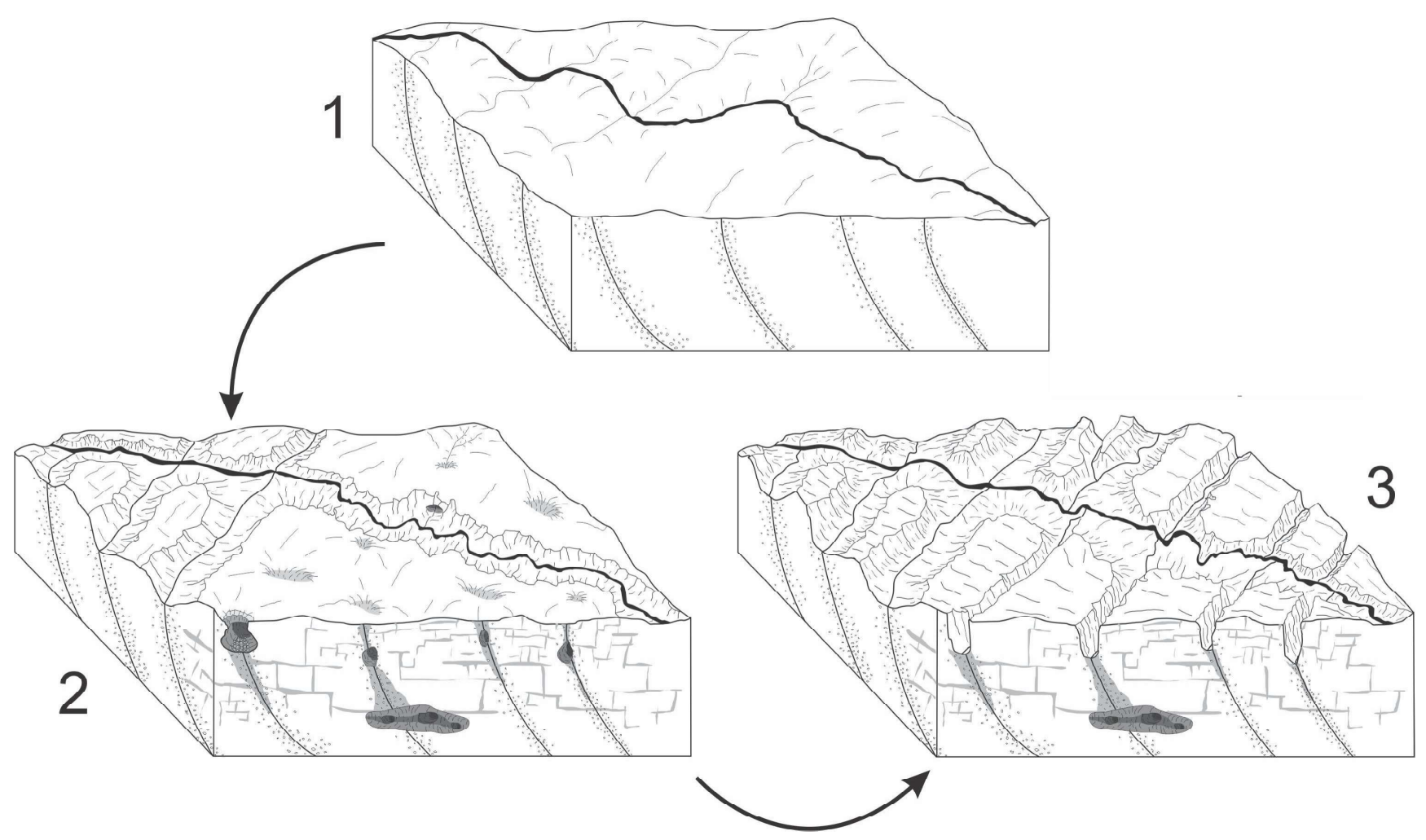

Figura 10 - Modelo de morfogênese de paisagem da Chapada das Mesas: Processos superficiais e subsuperficiais são importantes para a evolução do relevo da região. Estes últimos, devido à "carstificação" em lineamentos de arenitos, formam ductos e cavernas que, ao colapsarem, potencializam a formação de vales encaixados. Desenhado por Henrique Amorim Machado.

\section{Considerações Finais}

Ao final deste trabalho foi possível concluir que a região da Chapada das Mesas constitui uma paisagem que teve uma morfogênese muito mais complexa do que o previsto para modelos evolutivos do relevo para paisagens do tipo Chapada. Destaca-se uma gênese em parte associada à ocorrência de formas e a dinâmicas cársticas. Logo, a superfície somital arenítica é recortada e dissecada graças não somente à incisão fluvial de canais de baixa ordem ao longo dos lineamentos estruturais, mas também em razão da evolução de drenagens subterrâneas que em estágios avançados tem seus tetos desabados e são exumadas. Paralelamente, o presente trabalho mostrou que algumas das paisagens do tipo Chapada podem ser consideradas como poligenéticas e que processos típicos do carste podem ser geradores desse tipo de paisagem, mesmo em áreas de substrato não carbonático. Tal consideração abre a possibilidade de revisão de todo o conhecimento nacional acerca das chapadas.

\section{Agradecimentos}

Agradecemos ao CNPq (Projeto Universal 446857/2014-9) e a CAPES (Projeto CAPES COFECUB 869-15) pelo apoio financeiro. Agradecemos também a Édipo Henrique Cremon (UFG) e Fábio Correa Alves (INPE) pelo auxílio nas análises em ambiente MATLAB. Por fim agradecemos a Henrique Amorim Machado pelo apoio no desenho de algumas figuras.

\section{Referências Bibliográficas}

ALMEIDA, F. F. M.; HASUI, Y.; BRITO NEVES, B. B.; FUCK, R. A. Brazilian structural provinces: an introduction. Earth Science Reviews, v. 17, p. 1-29, 1981. DOI: 10.1016/00128252(81)90003-9

BARRETO, A. B. C.; MONSORES, A. L. M.; PIMENTEL, J. Modelo de favorabilidade hidrogeológica em aquígeros fissurais - a utilização de técnicas de geoprocessamento no cristalino do estado do Rio de Janeiro. In: IV Simpósio de Hidrogeologia do Nordeste. XII Encontro Nacional de Perfuradores de Poços. 2001. p. 467- ,475. 
BRASIL 12 DEZ. 2005. Decreto de criação do PARNA chapada das mesas http://www. planalto.gov.br/ccivil 03/ Ato2004006/2005/Dnn/Dnn10718.h̄tm

BRAUCHER, R.; MERCHEL, S.; BORGOMANO, J.; BOURLÈS, D.L. Production of cosmogenic radionuclides at greath depth: a multi element approach. Earth and Planetary Science Letters, v. 309, p. 1-9, 2011. DOI: https: 10.1016/j. eps1.2011.06.036

BROWN E. T., STALLARD R. F., LARSEN M.C., RAISBECK, G. M., YIOU, F. Denudated rates determined from accumulation of in situ produced ${ }^{10} \mathrm{Be}$ in the Luquillo Experimental Forest, Puerto Rico. Earth Planetary Science Letters, v. 129, p. 193202, 1995. DOI: 10.1016/0012-821X(94)00249-X

COX, R. T. Analysis of Drainage-basin symmetri as a rapid technique to identify areas of possible Quaternary tilt-block tectonics: An example from the Mississipi Embayment. Geological Society of American Bulletin, v. 106, p. 571-581, 1994. DOI: 10.1130/0016-7606(1994)106<0571:AODBSA $>$ 2.3.CO;2

GRANGER, D.E.; KIRCHNER, J.W.; FINKEL, R. Spatially averaged long-term erosion rates measured from in situ-produced cosmogenic nuclides in alluvial sediment. Journal of Geology, v.104, n. 3, p. $249-257$, 1996. DOI: $10.1086 / 629823$

GONZALEZ, V.S.; BIERMAN, P.R.; FERNANDES, N.F.; ROOD, D.H. Long-term background denudation rates of southern and southeastern Brazilian watersheds estimated with cosmogenic 10Be. Geomorphology, v. 268, p. 54-63, 2016. DOI: 10.1016/j.geomorph.2016.05.024

HARE, P. W; GARDNER, I. W. Geomorphic indicators of vertical neotectonism along converging plate margins. In: Annual Binghamton Geomorphology Symposium, Anais. Boston, 1985.

INTITUTO BRASILEIRO DE GEOGRAFIA E ESTATÍSTICA - IBGE. Mapa de Unidades do Relevo do Brasil. Escala 1: 5.000.000, 2006. Disponível em: <ftp://geoftp.ibge.gov.br/ mapas_tematicos/mapas_murais/relevo_2006.pdf $>$. Acesso em: 20 jun. 2014.

MARTINS, F. P.; SALGADO, A. A. R.; CARMO, F. F.; MAFRA M. A. As chapadas brasileiras e a legislação ambiental: conflito de conceitos. Revista Brasileira de Geomorfologia, v.16, n.3, p. $387-398$, 2015. DOI: $10.20502 /$ rbg.v16i3.678

MARTINS, F. P.; SALGADO, A. R. A. Chapadas do Brasil: abordagem científica e conceitual. Revista Brasileira de Geomorfologia, v. 17, n.1, p. 163-175, 2016. DOI: 10.20502/ rbg.v17i1.806

MINISTÉRIO DO MEIO AMBIENTE; INSTITUTO BRASILEIRO DO MEIO AMBIENTE E RECURSOS NATURAIS RENOVÁVEIS; CENTRO NACIONAL DE PREVENÇÃO E COMBATE AOS INCÊNDIOS FLORESTAIS. Plano operativo de prevenção e combate aos incêndios florestais do Parque Nacional da Chapada das Mesas. 2007.

MORAES, R. C e LIMA, L. P. Utilização de SIG como ferramenta na gestão do Parque Nacional Chapada das Mesas (Carolina/ MA). In: Anais XIII Simpósio Brasileiro de Sensoriamento Remoto. Florianópolis, Brasil, INPE. 2007. p.4057-4064.

LAL, D. Cosmic ray labeling of erosion surfaces: in situ production rates and erosion models. Earth Planetary Science Letters, v. 104, p. 424-439, 1991. DOI: 10.1016/0012-821X(91)90220-C

SALGADO, A. A. R.; MARENT, B. R.; Cherem L. F.; BOURLÉS, D.; SANTOS, L. J. C.; BRAUCHER, R; BARRETO, H. N. Denudation and retreat of the Serra do Mar escarpment in southern Brazil derived from in situ-produced ${ }^{10} \mathrm{Be}$ concentration in river sediment. Earth Surface Processes and Landforms, v. 39, p. 311-319, 2013. DOI: 10.1002/esp.3448

SALGADO, A.A.R.; BUENO, G.T.; DINIZ, A. D.; MARENT, B. R. Long-Term Geomorphological Evolution of the Brazilian Territory. In: VIEIRA B.C.; SALGADO A.A.R.; SANTOS. L.J.C. Landscapes and Landforms of Brazil, London: Springer, 2015, p. 19-31.

SALGADO, A.A.R.; REZENDE, E. de A. ; BOURLÈS, D.; BRAUCHER, R.; DA SILVA, J. R.; GARCIA, R. A. Relief evolution of the Continental Rift of Southeast Brazil revealed by in situ-produced 10Be concentrations in river-borne sediments. Journal of South American Earth Sciences, v. 67, p. 89-99, 2016. DOI: $10.1016 /$ j.jsames.2016.02.002

STRAHLER, A.N. Dynamic basis of geomorphology. Geological Society of American Bulletin, v. 63, n. 9, p. 923-938, 1952. DOI: 10.1130/0016-7606(1952)63[923:DBOG]2.0.CO;2

VALERIANO, M.M.; ROSSETTI, D.F. Topodata: Brazilian full coverage refinement of SRTM data. Applied Geography, v. 32, p. 300-309, 2012. DOI: 10.1016/j.apgeog.2011.05.004

VILLELA, S.M.; MATTOS, A. Hidrologia aplicada. São Paulo: Mcgraw Hill, 1975. 250p. 